\title{
The sound of daylight: the visual and auditory nature of designing with natural light
}

\author{
D. J. Butko \\ The University of Oklahoma, College of Architecture, USA
}

\begin{abstract}
Students assemble in classrooms without windows. Parishioners attend services in enclosed buildings. Most people spend the majority of daylight hours inside buildings dependent upon artificial control systems without much connection to the benefits of natural elements - especially natural light.

What happened to design integration of the basic knowledge that sunlight is practically free to harness, that the human body relies upon the sun to produce essential Vitamin D, and that humans are innately attracted to the outside world? Some designers have been convinced that energy efficiency overrules basic human needs. Others deem exterior views and natural light to be distractions for building occupants. Conversely, comprehensive design incorporates precisely layered assemblies of materials to be energy, thermally, and sustainably efficient. Natural light can truly define spatial character. Building orientation, fenestration, material surfaces, and ceiling heights all contribute to how natural light will dwell in each space. Design decisions can also affect other considerations such as acoustical properties and the overall experience conveyed to the occupants. Natural lighting is a dynamic design tool that can be an integral part of initial sketches through project design development. Fundamental principles of reflection, refraction, diffusion, and absorption are applicable to both natural lighting and acoustics. This paper will challenge designers to create space where natural light is integral to the building's enclosure and acts as a catalyst to provide acoustical benefits as attention is focused on material selection, arrangement, and detailing. Proposals will be based on precedent studies, current research, and derived from teaching architectural acoustics and natural lighting courses.
\end{abstract}

Keywords: natural light, daylight, design, building materials, sound, acoustics, architecture, architectural. 


\section{Introduction}

Seeing and hearing are two primary senses that affect human behavior, attitude, and health. The entire human body is influenced in several ways by the interaction between visual and auditory nuances. Human senses are stimulated by nature, artwork, music, sculpture, and other social forms of expression. Unfortunately, the general public, and sometimes the designers entrusted to developing functional space, do not fully understand how people can be individually and collectively affected by lighting and acoustical environments.

Numerous architects throughout history, in both professional practice and academia, have referred to architecture as the "mother of all arts." Regardless whether everyone agrees with this statement or not, architecture is responsible for housing specific functions and defining character for inhabitable enclosures in which most of the world's population spend the majority of their time. Studies suggest that people spend more than 80 percent of life indoors (Baker [1]). We live life within the art form of architecture, so the built environment should ultimately serve the occupants and be environmentally responsive throughout initial design schemes, construction, habitation, and maintenance phases. However, serving the occupants is more than just providing a building that defines enclosed conditioned space. Architecture is what happens when the mundane need for enclosure to accommodate a specific function becomes energized with how that specific function can be tailored to the occupants. Natural lighting is a design tool that addresses numerous physical, emotional, and spiritual needs while animating various building types.

Some architects understand the bigger picture, and some do not. Famed architect Le Corbusier stated, "Architecture is the learned game, correct and magnificent, of forms assembled in the light" [2]. How those forms are assembled can define unique lighting and acoustic qualities simultaneously. Architectural lighting expert William Lam has spent many decades educating architects and the general public about natural light and has characterized a common issue:

At the beginning of my career as an architectural lighting consultant, I wrote a series of articles in Architectural Record, "Lighting for Architecture" (1959-60), to remind architects that the uncomfortable, unpleasant, unattractive luminous environments characteristic of most of their new buildings were the result of their abdication of lighting design to engineers untrained in design (Lam [3]).

As Lam argues, the disciplinary divisions between architects and lighting engineers are partly to blame.

Most portions of buildings that differ from the traditionally expected enclosure aided by electrical and mechanical systems are typically viewed as "artistic" or "creative" gestures frivolously designed by the architect and are regularly viewed by owners and contractors as unnecessary for basic building function. Cost-cutting measures, instigated by team members who do not value what they deem as "artistic gestures," diminish intricate details in the name of value engineering. The building and future occupants are stripped of vital design 
concepts aimed at supporting the intended usable function, and consequently the occupants' welfare is negatively affected. Architects should desire to understand how and why natural light is important and then convey those reasons to the client. When architects design buildings, the resultant spaces need to be more than simple enclosure from the outdoor environment.

Serving human psychological and functional needs is the aim of all architecture. Buildings are built to serve people. Therefore they should enhance the quality of life for their inhabitants and facilitate a healthy environment. Unfortunately, that is not always the case.

Without question, a causal relationship exists between the indoor environment and human health. The effects of poorly designed buildings, whether in terms of limited access to sunlight or poor indoor air quality, continue to affect the health of building occupants. Sick Building Syndrome (SBS) is frequently associated with issues of indoor air pollution, the absences of sunlight or daylight, inadequate heating or ventilation, poor acoustics, and the presence of asbestos. Lack of sunlight combined with high humidity can trigger the formation of mold and mildew spores, airborne contaminants that may lead to respiratory diseases (Boubekri [4]).

The title of this paper, "The sound of daylight," refers to two concepts. First, the selection, articulation, scale, and locations of materials will define how both light and sound exist in a space. Materials determine the behavior and interaction of light and sound within defined space. Second, personal interaction is an important factor to consider in defining a space. How people use the space and interact with other people results in variations of lighting and acoustical environments. There are universal physical and emotional factors associated with both lighting and acoustics for all buildings and occupancy types, such as health, well being, emotions, production of vitamin D, diurnal patterns, circadian rhythms, task productivity, and sustainability.

Architecture itself can express zeal and become evocative for its function and occupants. The material choices, layers of material assemblies, and spatial relationships among adjacent materials can define a specific and tailored architectural language. Over the years people have learned to create, control, and manipulate artificial light; natural sunlight, however, still stimulates the human spirit (Slingerland [5]). Natural light in architecture can be used to define both visual and acoustical qualities as an expression of purpose while appealing to our senses and meeting human needs.

\section{We are visual people}

The general public acknowledges visual and thermal discomfort more than acoustical discomfort. Temperature and/or lighting variations within a space typically result in more complaints than do acoustical issues, yet all three areas are intrinsically linked. Mechanical and electrical systems are intrinsically depended upon for human comfort in most occupancy classifications without much concern for natural lighting or passive heating and cooling options. Consequently, poor acoustics are usually deemed as the unavoidable result 
because most people do not associate noise and acoustical problems with architectural design.

The media is first in line to appeal to our visual nature. Television, printed media, and the Internet heighten our attention to visual culture and experiences. Even most modern music is marketed to appeal first to our visual sense rather than focusing on audio content or musical talent. The performer's clothing fashion, stage set, or hairstyle can create fans. Society has become obsessed with beauty being defined as how something appears to someone else, yet most current architecture is being publicized as the bare essentials of enclosure without much regard for visual appeal. Consequently, the general public is not accustomed to seeing, inhabiting, and experiencing architecture that combines function, beauty, and environmental concerns. The architecture in which people spend most of their lives violates our innate need for natural elements and the beauty they define.

Typically, architecture and design magazines show the glamorous side of a select few buildings in an attempt to convey beauty. The media usually wants to portray the building, or at least the inviting views of the building, as "good design." How could a photograph begin to address the age old question: what is good design? Aside from critics' and armchair architects' social commentary on the imagery, there is another layer of hidden information in those photographs. Good design can be more than what human eyes relate to human brains. The subdued layer of architecture experienced with human ears cannot be appreciated solely through the visual medium, but it can be complementary to natural lighting schemes. People need to hear what architecture creates.

\section{How do lighting and acoustical environments relate?}

Natural light within buildings is all too often the result of simple, punched openings, usually referred to as "windows," in a planar wall. Aside from music halls and recording studios, room acoustics are usually the resultant by-product of other design decisions without finely focused attention to how the finished space will sound to the occupants or how certain adjacent sounds need to be attenuated. Light and sound both travel in waves, and they behave in similar manners when exposed to various wall assemblies, materials, and finishes. They share the reactionary components of reflection, refraction, diffusion, and absorption. Lighting and acoustics share great potential as crucial functions in programmatic design requirements.

Light is a form of energy that permits us to see. The quality of that light then determines what we see and how we feel within that space. Acoustics is the auditory complement to the visual nature of light. Human emotions are sparked by both light levels and acoustic conditions. These waves of frequencies are not stagnant - they are ever-changing. The natural variation of tones is cast through the atmosphere throughout a typical day from sunrise to sunset. The light is filtered and altered as it passes through, reflects, or refracts in typical atmospheric conditions such as rain, snow, and clouds. The Polish cosmetics industrialist Helena Rubinstein concisely stated, "Daylight reveals color; 
artificial light drains it" [6]. The same can be said in relation to natural acoustics.

Along with numerous other issues, architects are charged with the insightful task of selecting and arranging materials for structural, functional, and aesthetic purposes. Here lies common ground. Those chosen materials and subsequent relationships - which at first glance may simply appeal to our senses and appear beautiful or artistic, or may merely define scale and enclosure - suggest specific spatial lighting and acoustical environments. The visual association with surfaces and how the materials are articulated allow the specific dwelling of light. Decisions about materials also relate to the auditory nature of the space. Observers and occupants begin to comprehend the communion of natural light and natural acoustics as they share similar details.

There are various terms associated with defining acoustical qualities, but the most common is reverberation. Simply defined, reverberation is the persistence of sound after the original sound has stopped. Classrooms should have approximately half a second of reverberation time for speech intelligibility, while Gothic cathedrals typically have three or more seconds to suit various styles of chanting. Reverberation time calculations are directly based on the total room volume and inversely associated to absorption values of individual surface areas. Acoustically reflective materials create a lively space with longer reverberation times while acoustically absorptive materials deaden the space and do not allow much reverberation. It is possible for small volumes with highly reflective materials to have more reverberation time than mostly absorptive larger rooms. Since room volume and surface finishes define basic acoustical qualities, it is easy to understand where natural lighting and acoustics begin to coexist. Basic descriptive terms such as piercing, diffused, soft, hard, warm, cool, bright, and dull are ways to conceptualize both lighting and acoustical environments.

Layering and transparency of materials blur the visual and auditory separation between spaces. How these materials relate with light and acoustics define a specific character. Every space has its own signature environment dependent upon how light and sound waves interact with materials. This occurs at a physiological level where human senses interpret orientation, scale, and subtleties of spatial definition (Sheridan and Van Lengen [7]). The aural perception of space contributes to the experiential identity of an environment.

\section{Sustainability}

The United States Green Building Council (USGBC) defines sustainability as "meeting the needs of the present without compromising the ability of future generations to meet their own needs" (United Nations [8]). This is a generalized definition applicable to most areas of design and construction. What do acoustics have to do with sustainable design efforts, especially pertaining to natural lighting? Although acoustics are generally left out of most sustainability directives, spaces designed with poor acoustics can have deleterious effects on the function of a building. Relative to acoustics, "People's satisfaction was actually slightly lower in green buildings than in regular buildings," says Ken 
Roy, senior research scientist and acoustician at Armstrong World Industries. Not only are acoustics often ignored when creating a green building, but they are also ignored by the organizations defining green buildings (Madsen [9]).

Although draft standards with some acoustic requirements are under consideration, quantitative acoustic design requirements are not included in current sustainable design standards. The question arises as to whether a building that is not comfortable acoustically, and therefore not fit for its purpose, is actually a sustainable building for its occupants (Field [10]).

In other words, while acoustic consideration may not directly influence energy consumption or life cycle costs, acoustical properties of spaces do have the ability to influence users' behavior in positive or negative ways. While it may be difficult to evaluate quality of design as a property of space in industry standard sustainability terms, aesthetics and spatial quality should not be ignored entirely in favour of quantitative and measurable data associated with sustainability.

Natural lighting and carefully considered acoustics can contribute to an artistically sustainable expression tailored to the intended users. Since daylight is practically free, aside from costs associated with blocking heat gain and UV rays, we should use it more frequently.

According to the 1998 Energy Information Agency of the U.S. Department of Energy, the building sector is responsible for about 36 percent of all the energy consumed in the United States, more than the transportation sector ( 27 percent) and an amount almost equal to that used by the industrial sector (38 percent). Lighting is responsible for 30 percent to 50 percent of all energy utilized in commercial and office buildings [4].

Natural light can provide numerous benefits including less dependence on artificial light and hence fossil fuels, incorporation of solar collector panels to convert natural light into usable energy, and, in some climates, aiding in passive heating and cooling needs. Creative and aesthetic uses of natural light not only benefit occupant health and welfare, but the building's carbon footprint also decreases. Humans possess an innate attraction to nature. When natural elements are used in building design, our buildings become more sustainable and connected to their local environments.

\section{Studies and statistics}

Various studies have examined the effects of both light and acoustics on human beings, yet most designers are either unaware of the studies or do not find value in the results. Human health, productivity, comprehension, and overall happiness are all directly linked to appropriate levels of light and sound throughout the day. Variations of light and sound levels influence learning and retention rates, fatigue, stress, strain, confusion, frustration, morale, absenteeism, illness, privacy, and productivity (Madsen [11]). In fact, the Occupational Safety and Health Administration (OSHA) regulates levels of illumination necessary for various tasks (i.e., visual acuity, occupant safety, egress, etc.) and limits exposure to certain sound pressure levels and frequencies. 
Direct sunlight can sometimes be counterproductive, so building design should admit the proper amount of sunlight, use it efficiently, and redirect it for balanced illumination and to avoid glare (Egan and Olgyay [12]). There is a vital difference between the direct light of sunlight and the diffuse light of daylight. Glare and overheating from the sun's direct rays is debilitating in areas where critical visual tasks are common (Loveland [13]). Most studies show natural light creating a positive atmosphere, but only when achieved with diffuse daylight. Studies have documented up to a 15 percent decrease in curriculum comprehension when direct sunlight is present in elementary classrooms [13]. There are also alarming statistics concerning acoustics and speech intelligibility. For example, according to a branch of the Acoustical Society of America (Technical Committee on Architectural Acoustics), the speech intelligibility in most U.S. classrooms is rated at 75 percent or even less (Seep [14]). This value represents how many spoken words a listener with normal hearing can typically understand during a lecture, discussion, or presentation.

As a professor of architecture, I have observed a difference in retention rates among students due to variations in lighting and acoustical environments. Design studio is a large part of all architecture program requirements, yet the environment in which students are expected to spend most of their waking and sleeping hours is probably not always ideal for focused attention and retention rates. Most architecture design studios do not incorporate lighting and acoustical considerations into the design of the learning environment. Design studios are typically large open volumes with concrete floors and planar wall surfaces without much natural light. Some design studios are open to adjacent rooms, which only exacerbates the poor acoustics. Students are then directed to present their projects in open corridors or other locations in which their focus is subject to other students and/or environmental noises. Lecture classrooms are usually not much better. Typically hidden in the core of a building, the rooms are without windows and are not designed for natural acoustics. It is astonishing that most classrooms have parallel planar walls as this arrangement produces flutter echoes leading to decreased speech intelligibility. Selective sound reflection and absorption, raked seating (since good sight lines also produce good sound lines), and natural light should be standard in lecture rooms to enhance student comprehension. If the room is designed for optimum use of daylight with acknowledgement of basic acoustical properties, the finished space will be more accommodating for the function and occupants.

\subsection{Natural light}

The Heschong Mahone Group, a prominent research entity, appears to confirm what some school designers have asserted based on anecdotal evidence: children learn better under illumination from skylights or windows, rather than from light bulbs. The main theory for explaining this observation is that "daylighting" enhances learning by boosting the eyesight, mood, and/or health of students and their teachers (Heschong Mahone Group [15]). Natural light makes a quantifiable difference. 
An important light study for a mercantile environment was conducted in 1993 by a big box retail store in which the retailer experimented with environmentally based design strategies. The initial daylighting scheme included a large glass arch at the front of the store and skylights over the entire sales floor. In a costsaving move that resulted in a control group, the retailer decided to install skylights over only half the sales floor. To their surprise, sales per square foot were higher in departments in the day-lit side of the store, even higher than the same departments in other stores without skylights. Department managers whose departments were not under the skylights lobbied to have their departments relocated beneath them [15]. Simply stated, merchandise displayed under daylight attracted more sales.

Another informative study performed by the Heschong Mahone Group examined twenty thousand California, Colorado, and Massachusetts students between 1998 and 2002. Test scores increased as much as 26 percent among students who learned in classrooms filled with natural light [13]. Other statistics show that learning rates are on average 26 percent higher in reading and 20 percent higher in math in rooms with the most natural light.

A study from Alberta Canada, "A study into the effects of light on children of elementary school age," concluded that natural light has a positive effect on children's health. Children in classrooms with a natural spectrum of light had 1.75 fewer cavities than children in schools with traditional lighting. It also found that children exposed to high-pressure sodium vapor lighting were absent 3.2 days per year more than students in classrooms with full spectrum light (Hathaway et al. [16]). Psychologists and energy efficiency experts alike have long suspected that something as simple as sunshine may help people work more efficiently, learn more, call in sick less often, and sell more merchandise [15].

\subsection{Natural acoustics}

The Greeks and Romans studied acoustics and were successful with exploring shape and materials, but they did not express absorption and reflection in terms of mathematical equations in a manner that could be scientifically calculated. Since then, thousands, perhaps millions, of acoustical studies and experiments have been performed. The most influential study pertaining to mathematical calculations was performed by Wallace Sabine circa 1895. Mr Sabine, commonly known as the father of modern architectural acoustics, started his distinguished acoustical career studying the newly constructed Fogg Art Museum Lecture Hall at Harvard University that repeatedly produced over five seconds of reverberation. Typically, anything over one second of reverberation in a lecture hall reduces speech intelligibility. Students and faculty, without any acoustical training, instantly noticed the acoustics in the room were not conducive to understanding and learning presented information. As a young physicist, Sabine was appointed to research the room and conclude why such a long reverberation time existed.

Based upon lengthy experiments and research in the lecture hall, Mr Sabine developed the mathematical formulas for reverberation time and time delay gap along with the resultant acoustic behavior associated with building materials and 
surface contour shapes. He compiled data listing the absorption coefficient of various materials and material assemblies as direct contributors to reverberation time. Overall, his discoveries and innovations in the field of architectural acoustics are world renowned and the basis of modern acoustics.

\section{Designing and making with natural light and acoustics}

I use light abundantly, as you may have suspected;

Light for me is the fundamental basis of architecture.

I compose with light (Le Corbusier [17]).

Heat gain, temperature differences, wind pressures, dew point values, and relative humidity are all factors that an architect needs to know for schematic design and wall assembly types. These factors must remain at the forefront throughout construction and will ultimately help determine location and attachment of window, translucent panel, sun screen, and light shelf systems that allow natural light into interior spaces and contribute to room acoustics.

Sunlight serves as the link to the outside world when we are indoors, facilitating our essential connection with nature and giving us a sense of time and position in that daily cycle [4]. In addition to their environmental benefits, natural ventilation, fresh air, and natural light contribute to a sense of well being, as does a view to the outside (Boyle [18]). Consequently, initial site selection and programmatic studies are crucial to the successful use of daylight in design. For a design to benefit the most from daylight, natural light must be an inherent design tool throughout the entire design process. The entire team of designers, including clients, occupants, architects, engineers, consultants, and specialists, needs to communicate constantly to ensure the benefits of natural light are not lost or value engineered out of the development.

Acoustical and lighting properties interrelate in various manners. Tectonically constructed overhead planes and soffits typically used as sun screens and light shelves to promote reflection, refraction, diffusion, and absorption of natural light also offer opportunities for the development of acoustical properties. The perceived height and volume of space are decreased as these elements span from exterior to interior. More intimate and directional acoustics result as direct impulses travel less distance and encounter multiple surfaces that promote acoustical reflection, diffusion, and/or absorption at selective frequencies. Upper and lower light shelf surfaces can be articulated and contoured to define visual and acoustical room ambiance per the design intent. The architect can sculpt the manner in which light and sound waves react with various surfaces. Color, tone, and shadow can be expressed for both lighting and acoustics. What was once understood as one large room is now altered by tectonic elements that create varied dimensions and interaction. The lighting and acoustical decisions delineate implied spatial relationships.

Lighting serves various pragmatic, functional, and aesthetic purposes and is necessary to visually comprehend space. The design profession typically defines space as the void contained by enclosure, which can allow and contain both natural light and natural acoustics. Architects can use natural light as a design 
tool to create levels of intimacy, transition, comfort, visual acuity, and acoustical properties by the selection of materials and how they are arranged. Spatial definition can be the result of predetermined horizontal and vertical layers of materials and air cavities that allow natural light to pass from exterior to interior during the day, that allow artificial light to pass from interior to exterior during the evening, and that create a tailored acoustical environment that facilitates auditory intelligibility and attenuates unwanted noises.

\subsection{Acknowledgement of tangible examples}

There are countless designs and built examples showcasing natural lighting and natural acoustics. A select few architects have combined studies of lighting and acoustics that serve as inspiration to further research and innovation in this particular field. To name a few, architects such as Le Corbusier, Alvar Aalto, Louis Kahn, Richard Meier, Tadao Ando, and Juha Leiviskä have designed buildings such as Notre Dame du Haut (commonly known as Ronchamp), Vuoksenniska Church, Kimbell Art Museum, Church Dio Padre Misericordioso (commonly known as Jubilee Church), Church of Light, and Myyrmäki Church, respectively, where the lighting and acoustical environments are inseparable. These are just a few examples in which occupants are intentionally introduced to natural lighting and natural acoustics as a particular characteristic of the experience. The architects' attention to building orientation, materials, and construction details allows the finest level of lighting and acoustical intricacies to exist. The key to experiencing great architecture is taking time to look and listen at various times of day.

Ronchamp by Le Corbusier is typically taught as a unique example of form and light in architectural curriculums. It is exemplified as an icon of form. Aside from the lighting environment created from the room volume and deep recesses in the exterior wall leading to various sizes and colors of glass, there is also a definitive acoustical quality to the space. The large volume, extensive use of concrete, wooden pews, and splayed apertures all contribute to a sound that is undeniably Ronchamp. Vuoksenniska Church is usually described in terms of acoustical characteristics, yet Alvar Aalto commonly studied natural light and natural acoustics in tandem. Admirers of Aalto's work find the materials and surface contours working together to promote sights and sounds that are unique to his designs. Regardless of the building type or occupancy group, architects can incorporate natural light and natural acoustics to define a particular experience for the occupant within the specific function of the building.

\section{Summary}

Why start with daylight? One benefit is that lighting a space with daylight can make people happier, healthier, and more productive. In addition, if you turn the electric lights off, you can also save a great deal of energy [13]. Another benefit is that the thoughtful incorporation of both natural light and natural acoustics as codependent design strategies can ultimately make space the most functional for 
the intended purpose. Overall, design methodology needs to be broader than material choices based solely on single component values. Designers should choose materials that will allow layers of transparency for borrowed light among adjacent spaces, alter wall and ceiling slopes to help direct the light more efficiently, and tectonically assemble building components that provide necessary reflection, refraction, diffusion, and absorption for both lighting and acoustical environments.

When focusing on natural lighting, designers must consider numerous factors including site location, building orientation, climatic conditions, proposed time of day usage, heat gain potential, UV degradation, and other concerns. As decisions are made for natural lighting, architects and designers can also assimilate acoustical parameters not only to reduce dependence upon artificial lighting and sound reinforcement systems, but also to enhance both the overall experience of being in that particular space and the health and welfare of the occupants. Shaping the space yields a specific result for the full benefit of both natural light and natural acoustics. Architecture that incorporates natural light and natural acoustics breaks from static environments and introduces changing conditions that will either elate or deflate occupant attitudes. Attention to detail is the key for the successful marriage between function and nature.

Although acoustics and lighting are traditionally considered as separate aspects of design, they are experientially interconnected. Both lighting and acoustical experts and architects have much to gain by considering acoustical and lighting qualities of spaces together. As the two natural elements are examined and employed for functional design, one begins to understand a sense of "hearing" daylight or the "sound" of natural light.

\section{References}

[1] Baker, P., Prescriptions for a Healthy House: A Practical Guide for Architects, Builders and Homeowners, Inword Press: Santa Fe, 1998.

[2] Jeanneret, C. E. (Le Corbusier), Vers une architecture, 1922.

[3] Lam, W.M.C., Sunlighting As Formgiver For Architecture, Van Nostrand Reinhold: New York, p. 464, 1986.

[4] Boubekri, M., Daylighting, Architecture and Health: Building Design Strategies, Elsevier: Boston, MA, pp. 144, 2008.

[5] Slingerland, A.L., A pinnacle of light, Stage Directions, 18(10), p. 24, 2005.

[6] Rubinstein, H., BrainyQuote.com, Xplore Inc. http://www.brainy quote.com/quotes/quotes/h/helenarubi362583.html

[7] Sheridan, T. \& Van Lengen, K., Hearing architecture: exploring and designing the aural environment, Journal of Architectural Education, 57(2), pp. 37-44, 2003.

[8] United Nations General Assembly Report of the World Commission on Environment and Development, 11 December 1987. www.un.org /documents/ga/res/42/ares42-187.htm 
92 Lighting in Engineering, Architecture and the Environment

[9] Madsen, J.J., Meshing green design with acoustics, Buildings, 104(7), p. 20, 2010.

[10] Field, C., Acoustic design in green buildings, ASHRAE Journal. 50(9), pp. 60-70, 2008.

[11] Madsen, J.J., Acoustics: absorb, block, and cover, Buildings, 100(7), p. 57, 2006.

[12] Egan, M.D. \& Olgyay, V., Architectural Lighting, McGraw-Hill: Boston, pp. 436, 2002.

[13] Loveland, J., Daylighting and Sustainability, Environmental Design \& Construction, 5(5), p. 28, 2002.

[14] Seep, B. and Acoustical Society of America, Technical Committee on Architectural Acoustics, Classroom Acoustics: A Resource for Creating Learning Environments with Desirable Listening Conditions, The Society: Melville, NY, p. 12, 2000.

[15] Heschong Mahone Group, Daylighting and Productivity, www.h-mg.com/projects/daylighting/summaries\%20on\%20daylighting.htm

[16] Hathaway, W.E., Hargreaves, J.A., Thompson, G.W., \& Novitsky, D., A Study into the Effects of Light on Children of Elementary School Age: A Case of Daylight Robbery, 2008. www.naturallighting.com/articles effects_of_lighting_on_school_children.php

[17] Jeanneret, C. E. (Le Corbusier), Precisions, on the Present State of Architecture and City Planning: With an American Prologue, a Brazilian Corollary Followed by The Temperature of Paris and The Atmosphere of Moscow, MIT Press: Cambridge, MA, pp. 266, 1991.

[18] Boyle, S., Borrowed from barns and churches, Alternatives Journal, 3(2/3), p. 20, 2007. 